\title{
New Horizons in Medical Ethics
}

\section{Confidentiality}

This final tape-recorded discussion was devoted to some current ethical problems of confidentiality. In their working papers, circulated before the discussion, a barrister argues that the duty of confidence exists in equity as well as in contract; Dr. R. D. Catterall, a consultant venereologist, that many non-medical workers do not have the same ethical standards as doctors; Dr. Ronald Gibson, a general practitioner, that at present one can only view the scene with alarm; and Dr. Barry Barber, a computer professional, that by themselves computers do not increase the level of confidentiality in any organization. The working papers are printed below, followed by the discussion, which was chaired by a member of the B.M.F. editorial staff.

\section{The Legal Aspects}

\section{A BARRISTER}

Just as with bankers and lawyers so with doctors, if their patients are to receive the best advice, they should feel able to speak freely. Indeed, the obligation of confidentiality becomes an implied term of the contract of service between them. Nothing concerning the relationship between them or what arises from it may be disclosed without the patient's consent, the only exception being where the doctor is directed to do so by a court. Only a court can compel a doctor to break a confidence against his and his patient's wishes. On the other hand, there may be occasions when the doctor is justified in breaking the patient's confidence in the public interest. The view that the doctor himself takes, however bona fide, of his patient's real interests is irrelevant.

The duty of confidence exists wherever there is the relationship of doctor and patient, including when the treatment is free or on the N.H.S., and it does not just extend to those situations where contractual relations bind the parties. It also exists in equity.

In a recent trades secret case Lord Denning said: "The law of confidentiality depends on the broad principle of equity that he who has received information in confidence shall not take unfair advantage of it. He must not make use of it to the prejudice of h:m who gave it without obtaining his consent."1 A doctor is therefore prevented outside the contractual relationship from disclosing the results of tests (say, for example, stored in a hospital computer) where those tests have been carried out on another doctor's patient and the result of the disclosure would be to lead to the patient being identified. Nurses and medical social workers who also have no contract with those under their care are equally bound by this equitable duty of confidence.
This two-fold duty in contract and in equity is a great deal more than a mere moral obligation. The doctor may have little to fear at present from the attitude taken by the G.M.C. to admitted breaches of confidence, but the patient has his remedy at law -namely, suit for damages and injunction to restrain further disclosure. Where he can show that he has suffered financial loss, damage to his reputation, or even mere embarrassment the damages could well be more than just nominal. The M.D.U. has in the past settled breach of confidence cases rather than risk pursuing them to court (where the result would be almost a foregone conclusion). In one case the Union paid the legal costs of a girl two years under the then age of majority of 21 who complained that the doctor she had consulted told her parents that she was pregnant. With minors the right to secrecy and the right to treatment go hand in hand. The Family Law Reform Act 1969 established that a patient over the age of 16 can effectively consent to treatment without the necessity of requiring the permission of his parent or guardian. This places school doctors in a difficult position where, for example, they have to treat a 16-year-old sixthformer on the pill. If, as many doctors feel that they were bound to do, they informed the headmistress, the disclosure would clearly be unlawful. The fact that the doctor had his own estimate of the child's best interests at heart, while relevant to the G.M.C.'s view of the ethical propriety, would afford him no defence in the courts. Consequently, since 1969 some school doctors have made a practice of requiring their sixth-form charges to sign an authority giving them the right to disclose their medical condition to the school if it is in the school's interest. But such an authority is valuless if obtained by any element of compulsion.

Only lawyers are provided with the privilege of being able to withhold their clients' secrets in the witness-box-and even then it is the clients' privilge, to be waived by the client, and not his own. Doctors and priests have no such privilege-not even when acting as marriage guidance counsellors. Doctors and hospital staff are compellable witnesses on subpoena and can be obliged to produce their records. What is more, under a recent change in the Rules of the Supreme Court they can now be ordered to produce records in advance of the actual trial. ${ }^{2}$ But the court has a dis- 
cretion and will not order a breach of confidence unless the vital interests of justice demand it. In the case of the two journalists who refused to reveal their sources of information to the Vassall tribunal, Lord Denning stated: "The judge will respect the confidences of the medical profession received in the course of it and will not direct a doctor to answer unless not only is it relevant but also it is a proper and indeed necessary question in the course of justice to be put and answered."

In the United States rule 221 of the Code of Evidence gives doctors a privilege in civil actions and prosecutions for lesser crimes where the confidence has been reasonably necessary for the treatment in hand. Protagonists of a similar rule here have argued that the community's health (which requires the patient's candour at all times) is just as important as the administration of justice. But the undesirability of allowing litigants to lock up the truth in the mouths of their advisers and the basic respect which the courts have for medical confidences militates against any change which would result in an inflexible position.

There are several cases where it seems to me as a layman that confidences are nat always nowadays observed. One obvious instance is the writing of memoirs. In 1820 Lord Eldon in a case involving the publication of an engraving of George III on his death-bed said: "If one of the late King's physicians had kept a diary of what he had heard and seen, the Court would not in the King's lifetime have permitted him to print or publish it." The B.M.A. Code emphasizes that the obligation continues after death of the patient. But what G. M. Trevelyan urged on Lord Moran in relation to his book on Churchill ("It is inevitable that everything about this man will be known in time. Let us have the truth."') has considerable force.

Another example concerns factory and school doctors. Their obligations are and should be to their patient and not to their employer and sometimes they will be placed in a dilemma by their dual loyalty. It is as vital that their records should not be open to inspection by their employers at will. This is especially important where any question of compensation for industrial injuries arises between employer and employee. In preceding paragraphs I have dealt with another frequent example of broken confidences: those of children over 16 but not yet emancipated from the family home.

Doctors in charge of patients with mental illness also face considerable problems. If there is doubt about their patients' ability to handle their own affairs, their consent to disclosure should not be relied on. Their solicitor, relatives, or even the Court of Protection should be contacted. In particular, a doctor should not disclose information about the treatment of the patient to the spouse who is contemplating divorce -even when the object is to prevent the patient from being bothered. ${ }^{\circ}$

Since 1967 the doctor's duty to give information to the police has changed. Nowadays, doctors should bear in mind that where suspects refuse consent to medical examination, the doctor should refuse to make a statement based on his observation of the suspect other than to advise the police if he requires hospital attention. There is no legal compulsion upon him to provide information concerning criminal abortion, venereal disease, or attempted suicides. The Criminal Law Act 1967 abolished misprision of felony and there is no enforceable duty at all to give information to the police. Silence in answer to police inquiries does not amount to obstruction. Finally, there is the protection of computer records, where the patient can be identified. This is the responsibility of the supervising doctor. The B.M.A. says the matter is becoming increasingly urgent and Dr. Catterall, whose working paper voices doubts of the ethical standards of nonmedical workers, bears this out.

Conversely, there are cases where the doctor is quite clearly justified in breaking a confidence. These examples come to mind:

(a) The statutory obligation to notify infectious diseases.

(b) Any disclosure to third parties to protect them against the risk of infection to which the patient is exposing them. Even though there is a statutory provision for secrecy in the treatment of venereal disease and a patient has been treated under the scheme, details about his condition must be given in court if demanded.

(c) Epileptic drivers: doctors ought to tell the licensing authorities far more often than they do now if their patients are unfit to drive cars. Failure to do so will one day lead to a clarm against a doctor in negligence by a plaintiff injured by the doctor's patient who should never have been allowed on the road. Similarly, doctors should be less reluctant to tell the authorities of any traits in mental patients they are treating which present a potential danger to the public.

(d) Battered babies: giving information to the local authorities or the N.S.P.C.C. is obviously legitimate.

(e) Drug addicts: doctors would be justified in giving evidence which came to light about the source or supply of illicit drugs.

\section{Special Position of Venereology}

\section{R. D. CATTERALL}

Doctors and medical students normally show little interest in the question of confidentiality and there is a general lack of legal knowledge within the profession. Recently, however, there has been increasing anxiety about the introduction of mechanical and electronic techniques in record keeping, and access to medical records is available to a growing number of non-medical workers in hospitals and elsewhere. Many of these employees do not have the same ethical standards or traditions that have been commonplace among doctors for centuries.

The well-known fact that doctors rarely if ever improperly disclose information obtained in confidence from patients sometimes results in lawyers arranging to subpoena nonmedical persons-for example, records officers-to produce the medical records in court. Such people have no obligation to preserve confidence, though the medical consultation described in the hospital notes will have taken place under circumstances of implied confidentiality.
In some specialized branches of medicine secrecy has special importance-for example, psychiatry and venereology. Medical secrecy became statute law for the first time in the Venereal Diseases Regulations of 1916, which state that all information from persons treated for these diseases shall be regarded as confidential. This was restated in the National Health Service (Venereal Diseases) Regulations of 1948 and modified in the National Health Service (Venereal Diseases) Regulations of 1968 to permit information to be communicated to another medical practitioner or to a person employed under the direction of a medical practitioner in connexion with the treatment of those diseases.

Young people present special problems, particularly over sexual matters. The prescribing of oral contraceptive pills to young girls without disclosing the fact to their general practitioners or parents, abortions performed on girls under the age of consent, and the examination of girls under 16 for sexually transmitted diseases lead to problems of medical secrecy and disclosure.

Should the contents of the medical records of a patient who has attended a clinic for venereal diseases ever be disclosed without the written consent of the patient? A judge may rule that they should be disclosed, but the physician 
may feel that such a disclosure would strike at the very basis of his specialty and seriously damage the public image of the clinics. Perhaps a test case will be the only way to resolve this problem.

Lawyers are not obliged to reveal their client's secrets. The clergy of the Church of England are protected by the
Canon Law of 1603-4. But priests and clergy of other denominations are never asked to give evidence in court on confidential matters. Doctors, on the other hand, are often asked to do so. Does this mean that doctors have the reputation for giving way when pressed and should the medical profession re-examine its position on confidentiality?

\section{An Alarming Scene}

\section{RONALD GIBSON}

In general practice, once a doctor enters into a partnership with another doctor, once he works in close association with a health visitor, nurse, or midwife, or takes on his first receptionist, confidentiality-as Hippocrates knew and described it-becomes at risk. The modern tendency is for doctors to work in groups and in health care teams with members of other caring professions. This is a wholly admirable concept, contributing greatly to a fulfilling life for the doctor and total care of the patient, yet it carries with it a real danger that the safeguarding of patients" secrets-which "should not be published abroad"-will become increasingly difficult to guarantee and control.

It is in fact surprising, as the machinery of care has become more complicated and sophisticated, inevitably embracing more and more caring personnel, that any degree of confidentiality still remains. Even so, the cynics may say that what does remain is a mere facade. The saving grace is that the main professions concerned-doctors, nurses, health visitors, and midwives-all have a long tradition based on the dignity-almost the sanctity-of the interpersonal relationship between them and their patients. With medical secretaries and receptionists able to obtain their diplomas at technical colleges, and working closely with doctors and nurses, there is a hope that as the years go by and as the concept of the total care by a health care team advances and becomes traditionally more familiar, confidentiality will become more secure. But at present one can only view the scene with some alarm.

Until recently, there was one built-in safeguard; there was

\section{Wanted: A Confidentiality Clause in Staff Contracts}

\section{BARRY BARBER}

Though the introduction of computers often highlights particular problems of confidentiality, they do not by themselves improve or decrease the level of confidentiality obtaining in any organization. Decisions about access to particular records are primarily the concern of the computer user, not of the computer professional. The users can specify what records will be made available, under what conditions, and who may see them. In respect of medical information, the medical staff must obviously select who may see medical information and what information may be seen. The computer professional's interest lies mainly in spelling out the implications of these decisions and restrictions involved using current computer technology.

At least part of the security of present manual systems lies in the fact that they are individual, small-scale, dissem- one set of notes about one group of patients, all concentrated in one place away from the prying eyes of patients or strangers, yet available to all members of the team, and indeed securely guarded by them. Now, with the passing of the Social Services Act, the same patient becomes the responsibility of "Health" and "Social Security" (as if the patient himself was divided in two). A young profession is growing up in isolation, again-one hopes-building up a tradition of professional confidentiality, but separated as by a brick wall from members of the other caring professions. Now, in addition, there are two sets of notes about the same patient, kept in separate and separated buildings, each having a vital bearing on the total care of the patient yet each unseen by, and indeed unknown to, others involved in the total care.

Here there seems no hope that the years will bring anything more than increasing schism, which must inevitably have an adverse impact on the health and welfare of the patients and-worse still-on interpersonal relationships. The Social Services Act should be repealed.

As a further point, one must consider whether the people themselves place so much importance on confidentiality as did their ancestors. So many outside agencies require to know so much about the doctor's patient for so many reasons, that as life proceeds there is little left of "confidentiality"-and it could be said, little purpose in trying to preserve it. To this must be added the effect of the various media-particularly television-on the familiar image of the anonymous doctor and the traditional model of the doctor-patient relationship.

It may be that "progress" with all the advantages it is bringing and will bring to the health and welfare of the patient will claim, as its casualty, a destruction of the old and, until now, well-tried relationship between the doctor and his patient. One hopes not, yet doctors will need to fight hard for its preservation. inated, non-standard, and difficult for an outsider to use. In a computer system an appropriate level of security can be incorporated to ensure that the system is much more secure than present systems. The crucial question is: who may see what information?

As with any other system in which the medical staff do not write and store their own records, staff are required to operate the computer system. In the course of their work, they will see information in the reconds and they will have to handle the material in a responsible, professional manner. This has happened for years with nurses, pharmacists, biochemists, physicists, and medical social workers (to name but a few examples) and this is now happening with computer scientists. It also happens with medical secretaries and record clerks, and many other staff concerned with the functioning of the Health Service. A uniform clause inserted in the staff contracts would cover all groups, both medical and non-medical. Though computer science is a young profession, there is no reason to think that its professional standards are in any way inferior to those of the medical profession or other staff employed by the Health Service. The British Computer Society has, in fact, issued a code of practice and given a great deal of thought to the problems of privacy and confidentiality in practical terms. 
Turning to the reorganization of the Health Service, I find it difficult to see how the unified Service can provide better care unless appropriate information is made rapidly available throughout the district and possibly the area. Unified care can only mean multiple access to records. The key questions remain: (a) who may see what part of what record? (b) who may add to the record? (c) who may alter the record? From this follow two further questions: (d) how may individual patients (or citizens) be identified? (e) how may individual users of the system be identified? A computer system can offer great advantages in terms of record access and control but the answers to these questions will have to be written into the system from the beginning, not invented and modified in response to a sequence of practical queries over many years-as has happened with present manual systems.

As suggested by Bodenham and Wellman ${ }^{7}$-and many others -some form of computer-readable credit card could be arranged to identify both patients and staff to computer sys-

\section{Discussion}

BARRISTER: What the doctor must try to do where problems of confidentiality are concerned is to weigh the public interest in breaking the confidence against his patient's interest in keeping it. I can illustrate this by two separate examples: in the case of the pregnant girl over 16 there's no public interest in her parents being told-even the broad principles of sexual morality don't justify the breaking of confidence. The converse case is the dangerously epileptic or hypoglycaemic driver. Here the public interest is paramount. I disagree with the attitude of the B.M.F.'s editorial ${ }^{3}$ after the G.M.C. judgement on Dr. Browne, which said that what was at issue was the primacy of the general practitioner's professional judgement in assessing the patient's needs.

I think it's wrong that a doctor should inflict his own moral views on his patients and on the way in which he treats their confidences, and that a much more objective stand should be taken.

DR. GIBSON : I entirely agree. With a girl of 16-pregnant or on the pill-my duty is to her, and if I'm her family doctor she comes to me with her confidences and would never come again if I broke them. But usually if you know the girl, after one or two interviews you can persuade her to tell her parents.

DR. CATTERALL: One's first responsibility is to the patient, and venereologists sometimes have the problem that parents come round or telephone to say they want to know what's wrong with their son or daughter. We always refuse to give any information without the young person's consent, and if they're very insistent I occasionally try and arrange for them both to come and see me-but only with the patient's consent.

DR. BARBER: The consumer's interest must dominate the situation. But as well as disclosure in the public interest, there's also disclosure in the patient's interest-in that he may get better care if his full situation is known.

CHAIRMAN: What about the position of girls under 16?

BARRISTER: People over 16 are entitled to confidentiality because the Family Law Reform Act, 1969, has given them the right to treatment-and hand in hand with this goes the right to secrecy. But with children under 16 the doctor is legally, and probably ethically, justified in telling parents if their child is getting into some sort of sexual difficulty. And, of course, it is an offence for a man to have sexual intercourse with a girl under 16.

DR. GIBSON : But still you mustn't plunge straight away into spending for the parents, because you lose the confidence of your patient. It's often forgotten that every situation is different from every other one, and has to be treated on its merits. tems and give the appropriate level of access. Again, the emphasis must be on how much access to information is required to provide a high standard of patient care. The test is whether the standard of access provides good patient care and whether the risks of wider dissemination of information are balanced by the opposite risks of insufficient dissemination.

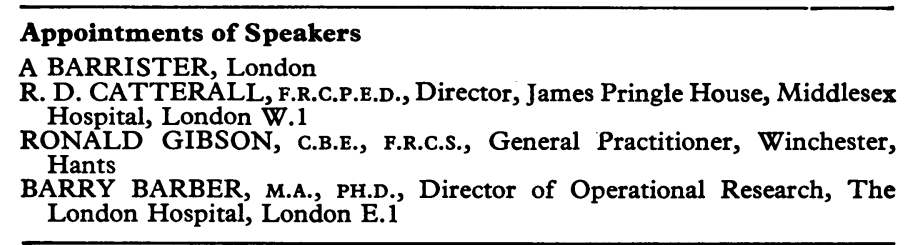

BARRISTER: It's interesting that Dr. Browne tried to justify his disclosure to the parents on the grounds that the girl was a patient, not a client. He said his patients consulted, clients instructed. ${ }^{9}$ I don't myself find this a convincing distinction.

CHAIRMAN: There is a difference in the derivation of the words: a patient is one who suffers, while a client is one who listens. Dr. Catterall, have you much experience in treating patients under 16 ?

DR. CATTERALL: The age of 16 is not a very good arbitrary age for consent, because young people are now maturing sexually much earlier. Venereology has a special problem, because quite a lot of girls under this age consult us and theoretically we're breaking the law every time we examine them. But obviously you can't ask the parents' permission in these cases. Some American state laws have actually been changed to exclude examination of children under 16 for suspected venereal disease from liability to charges of assault. Whether this is desirable in Britain or not I don't know.

DR. GIBSON: I find there's more pregnancy in girls of 14 or 15 than in those of 16 or over. By the latter age they've learnt to take precautions.

DR. CATTERALL: Yes-younger girls more often have venereal diseases as well as being pregnant.

\section{Telling the Family Doctor}

DR. BARBER: What's your policy about telling the family doctor?

DR. CATTERALL: If a patient has been referred by him, then of course we write a report to him. If the girl has a condition of long-term consequence, then we try to get her per$\mathrm{m}$ ission to write to him. If she refuses, then we would respect that.

CHAIRMAN: At what age would you respect her confidence?

DR. CATTERALL: 14 or 15 . There has been a case of a venereal disease clinic not respecting confidences in this age group, and letting parents know in every case, with the result that attendance figures dropped to a fraction of what they should have been.

Venereal diseases have, of course, enjoyed a special position, in that it's the first time that statute law has been involved in confidentiality. In general our legal colleagues are very understanding of our special position, but from time to time one is subpoenaed to appear in court; then you have no option but to take the records along and may have to disclose the details. I feel the patient may be being deceived here: he believed he was giving his history and being examined under a cloak of absolute confidentiality enshrined by the law-and yet the judge can reverse all this. The 